\title{
The Effects of Brain Drain Phenomenon under the Greek National Health System
}

\author{
Koukoufilippou Ioannis ${ }^{1}$, Bogri Damaskini², Soursos Georgios ${ }^{3}$, Koinis Aristotelis ${ }^{*}$ \\ ${ }^{1}$ Biomedical Department, General Hospital of Argolida, Argos, Greece \\ ${ }^{2}$ Nurse Department of Special Education for Children with Developmental Problems, Argos, Greece \\ ${ }^{3}$ Department of Urolog, General Hospital of Argolida, Argos, Greece \\ ${ }^{4}$ Psychiatric Department of General Hospital of Argolida, Faculty of Nurse University of Peloponnese, \\ Sparta, Greece \\ Email: *telis_psyc@hotmail.com
}

Received 15 January 2016; accepted 31 January 2016; published 4 February 2016

Copyright (C) 2016 by authors and OALib.

This work is licensed under the Creative Commons Attribution International License (CC BY).

http://creativecommons.org/licenses/by/4.0/

(c) (i) Open Access

\begin{abstract}
The phenomenon of the brain drain is a form of contemporary emigration consisting of the best section of the human capital of the country. The loss of productive dynamism at the highest level stymies the future prospects of the country. The National Health System is damaged immediately by the phenomenon as the country is deprived of talented young physicians, the very staff who comprises the "cadets" of the public health system. Motivation theories and empirical researches and motivation incentives in medical sector, are the basic tools of administration for the treatment of the phenomenon. Observing from the perspective of the administration of the hospital, it is understood that there is a wide range of actions that can act as a brake on the exodus of young scientists. A specific incentives package is proposed for implementation from the management.
\end{abstract}

\section{Keywords}

Brain Drain, Impacts, Motivation Theories, Motivation Incentives, Human Capital, Financial Cost, Emigration

Subject Areas: Sociology

\section{Introduction}

The loss of highly educated human capital in developing countries from 1960 until the present especially in medical specialities constitutes a problem for these countries [1]. In recent years, especially the phenomenon of the so called "brain drain" has also been observed within developed countries. The term brain drain describes

${ }^{*}$ Corresponding author.

How to cite this paper: Ioannis, K., Damaskini, B., Georgios, S. and Aristotelis, K. (2016) The Effects of Brain Drain Phenomenon under the Greek National Health System. Open Access Library Journal, 3: e2372.

http://dx.doi.org/10.4236/oalib.1102372 
the international transfer of resources in the form of human capital and it applies primarily to the migration of highly educated personnel from one country to another [2].

The phenomenon therefore concerns the human capital of the highly qualified particularly in specialities such as engineering and medicine which demand many years of education, training and professional experience. It concerns clearly the best part of the human resource potential of the country [3].

In the middle of the previous century, the country had experienced a large wave of emigration due to the prevailing difficult economic conditions particularly in rural areas after the war.

The difference with the phenomenon of the contemporary era is quality of their human capital which emigrated. In the past, emigrants came from the unemployed rural workforce of the country. Mainly, they were people with a low level of education, poor and without specializations that emigrated in order to staff the developing European industries after the Second World War.

In contrast to the present era in which the profile of the emigrant is that of a young graduate, highly educated, ambitious and talented who seeks a better quality of life and working conditions. Focusing on the phenomenon of the brain drain in the health profession and more especially amongst doctors that comprise the most highly trained and educated human capital of the country, it must be noted that it concerns a professional group linked with the wealth indicators, which function in intensive conditions with disproportionate ethical and material rewards. These professionals are welcome in other developed countries when they decide to emigrate. The destination countries are usually Germany and Sweden [3].

\subsection{Factors of Supply and Demand}

The demand for doctors in developed countries and mainly in countries of Northern Europe is larger than the domestic supply this is due to the percentage of doctors produced by the universities of the country, the changes and technological advances in medicine that require better educated and trained physicians in parallel with the rise in life expectancy and increased effort in the provision of better health services. The phenomenon of the brain drain is observed when:

1) There is a lack of medical staff in the reception country which is forced to import professionals from other countries. The medical profession in countries such as Germany is not popular because it requires great deal of effort and offers finally lower rewards compared with those received by engineers and industrialists. On the contrary in countries such as Greece there is an oversupply of physicians that is impossible to be absorbed in the domestic jobs market and then resort to working abroad [4].

2) An important economic benefit is produced in the country of reception as it is able to select physicians that reflect the criteria that are prescribed by the salaries that they wish to offer [5]. Thus educational resources are not expended as the best professional is admitted forthwith, ready to offer the specialty that is desired, at the requesting time [3] [4]. The UN calculates that the loss of economic resources at source, for an African migrant doctor is 184,000 dollars [5]. Unofficial reports calculate the average cost for every medical student in Greece is approximately 84,000 euro [4]. To this amount must also be added the living expenses, state benefit policies and the loss of taxes that surpass 100,000 euro for every six years of study.

3) There is movement from developed country to developed country against the backdrop of globalization and the global recession [3] [6]. This trend tends to be called brain circulation and describes the free movement of physicians [3]. In the case of Greece however this two-way movement of physicians does not exist due to the continuing economic recession. On the contrary the phenomenon of "flight" prevails. Already 6000 doctors have been lost and this is an increasing trend [7].

\subsection{Reasons for the Creation of the Brain Drain Phenomenon}

It has been observed that for every provisional reduction of domestic GDP by $1 \%$ emigration of physicians rises by approximately $0.3 \%$ [8]. Greece has been in economic recession for the last seven years, during which the GDP of the country has retreated greatly (reduction 20\%), unemployment and poverty have increased to unprecedented levels and the distortions of the education system, of the National Health System and of the jobs market have remain to their original state. Thus, usually the reasons for emigration are summarized as following:

- High unemployment [3];

- Economic recession [8]; 
- Personal economic reasons [8] and reduction in salary [3];

- Pathogenesis and problems of the National Health Service such as the manner of appointments,, the administration, the organizational culture, the bureaucracy [9];

- Medical population, the ratio of physicians is 6.1 per 1000 habitants and is the highest in European Union. In combination with only few appointments to positions in the National Health Service due to the obligations of the memorandum that requires one hiring for every five resignations and simultaneous shrinking of the private sector resulting in a large surplus of human capital [3];

- Chronic delay in the completion of training due to the wait for intake of specializations [3];

- Difficulties in the continuation of training [9];

- The working conditions in Greek hospitals [3];

- The conditions of globalization that make it easier for the transfer of professional physicians [2].

\subsection{The Population Group in Which the Brain Drain Phenomenon Appears}

As is natural the phenomenon does not affect physicians in their twilight of their careers. For a professional and family head it is a difficult decision to emigrate and there must be very important reasons to take this decision. On the other hand for a young physician that experiences restrictions and exclusion at the beginning of their career at the public hospital, at an age when they have not taken on family obligations, it is an easy decision to emigrate. The phenomenon therefore young talented physicians who for the reasons previously mentioned decide to emigrate [3].

The lack of a unified database in the country to record the human potential that emigrates hampers the accurate calculation of the extent of the phenomenon. The information is usually drawn from the statistical data of the reception countries that have detailed registration mechanisms [8]. If it is a question of calculating the amount of emigration of physicians then it must be taken into account the ratio $\mathrm{MBD}=\mathrm{A} / \mathrm{A}+\mathrm{B}$, where $\mathrm{A}$ is the number of physicians that emigrate and B the number remaining in the country.

When the ratio converges to 1 the phenomenon MBD (medical brain drain) increases, on the contrary when the ratio converges to 0 the phenomenon disappears [10].

\section{The Effect of the Brain Drain Phenomenon on the Public Hospital}

The brain drain phenomenon has important negative consequences the socioeconomic life of the country of origin. Focusing on the National Health Service it is a fact that apart from problems in economic resources, deficient infrastructure, lack of continuing training and low technical knowledge, the loss moreover specialized medical personnel creates dysfunction in healthcare units [5].

An immediate consequence is the overloading of the remaining medical personnel the undermining of their prestige and that of the Health Service [8]. The investment in the education of a doctor is of high cost to the country as it expends important economic resources for many years, as more than ten years is required for completion of training and specialization. This investment is totally lost in the case of the emigration of the physician [5]. Moreover the long duration of studies obliges both the family and the state to support the young person for at least fifteen years after adulthood, without contributing to the development of the country via employment, receipt of taxes and contributions to the social security system. On the contrary economic resources are consumed with the societal expectation of inclusion finally in the production process [5].

Moreover the phenomenon of emigration of young physicians leads automatically to the undermining of Greek university hospitals and medical schools as they are deprived of young capable and talented physicians, who will promote research work, develop new techniques and therapies which provide prestige and knowledge to them and to their institutions. In parallel these institutions and hospitals are deprived of capable physicians which immediately influences the level of healthcare [8].

Finally a social cost that often is not measurable and is rarely recorded in research is the effect of emigration on the family. The severing of the strong family ties that are common in Greece creates important mental and social trauma. Traumas sometimes are healed, with the return of the emigrant physician. The negative consequences are limited with the return of specialized human capital and the investment in education is not lost [5].

Simultaneously with the repatriation there is an important benefit that occurs from the importation of new ideas, the creation of new channels of communication with foreign institutions and important improvement in the level of service provision [5]. 


\section{The Role of the Theory of Motivation in the Thwarting of the Brain Drain Phenomenon}

Motivation is defined as an internal process of the creation of incentives of an individual in his effort and direction toward the achievement of his goals.

It is considered as one of the most important parameters of effectiveness and central management function [11]. Motivation is one of the factors of effectiveness, as are other factors such as capability of the workforce, the material and technical infrastructure and the suitable guidance influence greatly the overall performance of the employee and the organization [12].

Traditional forms of motivation are closely linked only with economic incentives or economic and social incentives (provision of enjoyable working conditions) and types of motivation to improve the interest aspect of work seem to provide little in the way of higher performance [11]. These forms of motivation however, with the support and provision continue to be popular enough even now [12].

After the observations of human behaviour opinions were developed regarding the theories of human need [12]. Amongst these Maslow's theory of hierarchy of need stands out, according to which a person is motivated by the meeting of certain needs in a certain list of hierarchy and only when the previous need is met is their effort to attain the next [13].

In Hertzberg's theory of two factors, which was based on research based in the workplace, the factors of motivation can be classified as incentives (motivation factors) and disincentives (maintenance factors). The disincentives do not lead to motivation but when not provided they function as a negative in regard to performance. On the contrary incentives are an essential factor of motivation that drives workforce improvement [14].

In McClelland's theory of fulfilling acquired need it is interesting to note that motivation is expressed in three fields of need [15]. The achievement of goals, the creation of bonds and authority-power are three parallel needs that the employee strives to fulfill [12]. Finally the theory of equality is worth a mention as it often concerns the workforce of healthcare units. According to Adams the employee compares his contribution with the result that he brings about, with the ratio personal result/personal contribution. When the ratio is less than one he feels it is unjust and when it is equal with one he feels that it is just and is satisfied. In parallel he compares his own ratio with his colleagues for checking the level of equality of the organization [16].

The combination of the above theories is the basis for the motivation of health professionals and the reduction of the brain drain phenomenon. The determination of the incentives that determine professional decisions of doctors is a mixture of these theories [11].

Focusing on the environment of the National Health Service in which the harsh working structure exhausts the low paid doctors and simultaneously limits their professional development, determines the greatest incentive [11]. These criteria are the springboard for suitable decision making with the basic tool being the comparison of theories of motivation previously mentioned. Placing in declining order of priority most important incentives, that determine the professional position of doctors, based on recent research work [11], it must be so.

The "achievement of aims" is the most important incentive and it is connected with concepts such as dignity, esteem, respect and social acceptance [11]. Even for physicians with many years of employment experience in National Health System, remains greater incentive than financial reward [9].

* The "cooperation” is the next important incentive for physicians as they need good work relationships with their colleagues and supervisors as derivation satisfaction [17].

* The "reward" for the provision is less important but remains a basic incentive because is related with the daily existence and the personal life [11].

* The "characteristics of work" is an important incentive and it comes from the characteristic of work that offers a plethora of perspectives. The physician is able to be concerned simultaneously with cure, research, authorial work, training, specialization, daily professional practice, and the acquisition of new techniques. This advantage of the profession is an incentive to the doctor and often offers new challenges, opportunities and interests for his work and science [11]. A particular role is played by the prevailing working conditions, including hours of work and working environment.

\section{Framework of Motivational Development at the Level of the Public Hospital}

The policy of incentives at the public hospital is limited due to the harsh fiscal framework that governs their function and determines the important questions such as salary levels and professional development. Thus the 
tradition tools of motivation are not at the disposal of the administration [11].

Despite these limitations however there are important marginal workers incentives from the administration and the hospital. With the basis of the comparison of the theories of motivation previously mentioned and the aforementioned incentives which are the most important for doctors the administration is able to formulate a dynamic motivational framework. Especially for the regional hospitals of Greece the prevision of incentives must start taking into account the theory of Maslow and provide newly qualified doctors with their basic needs in board and lodgings [13].

The conversion of some space into doctors accommodation and in addition a daily catering programme for new physicians is of negligible cost for the hospital. According to the theory of Hertzberg there are maintenance factors that although they do not motivate the employee there lack functions as a negative factor [14]. Included in these factors the administration must consider the programming of work. Flexibility in the work program does not require financial resources but creates the feeling of understanding and its importance on the behalf of the administration [11].

The theories of Hertzberg and Mc Clelland and other contemporary research define the most important incentive as the achievement of goals [14] [15].

In this are the administration ought to organize action and set goals in the medical workforce that lead to ethical rewards (granting of honorary titles or commendation in various fields of everyday work). Thus the doctor receives from the organization recognition and prestige granting him dignity, respect and social esteem [11].

The theory of Mc Clelland apart from the achievement of goals focuses on the creation of ties [15]. Collaboration as a motivation is next in terms of importance. Collaboration between head and subordinate, between colleagues of the same rank and between specialists is the foremost concern of medical management. However the administration is able to validate the work overseeing and intervening when it is appropriate, averting potential friction and at the same time placing clear boundaries in the aims and objectives of every department [11].

In parallel the creation of collaborative groups in all the spectrum of specialities that the hospital has offers, strengthening of personal relationships, the creation of bonds, realization of group goals and scientific development [11].

An important motivation of young physicians in order to strengthen their relationship with the medical unit and with mutual benefit, is the provision of continuing training, research, specialization and the learning of new techniques [11]. In this area the administration is able to organize and support presentations, conference days and discussions with medial themes in the environment of the hospital. The organization of seminars, meetings and workshops can be realized with the contribution of sponsors and the municipality as they contribute to conference tourism.

The creation of study spaces and digital libraries that will give young physician access to connect with other libraries in order to carry out small scale research and to write scientific articles and works, can be created based on the sponsorship and European funding. The creation of an educational office, which not prescribed in regional hospitals, potentially can function without supervision of the administration of the hospital but with the good will of some employees, will function as a communication hub and pinpoint all the possible post graduation seminars and activities that would interest young physicians. Administration ought to advance and encourage these actions.

The administration is able to admit the young physicians in to the decision making process that up until now they have been excluded from. In medical and administrative matters which concern their department, the expression of opinions and participation in decision serves as criterion incitement and is very useful in their Department [11].

Finally the fair and equal handling of all doctors regardless of seniority, rank or personality must be the policy of the administration in order to strengthen the feelings of equality and justice as is expressed in the theory of Adams [16].

\section{Conclusions}

No European policy is able to reverse the trend of emigration if it is to be supported the common economic development of the European Union. As long as the unemployment of the South increases, the brain drain phenomenon will be an alternative solution to the potential brain waste [4].

An inter-governmental policy would be able to limit the amount of movement of human capital between countries of the EU focusing on the agreement of reception countries on training expenditure of the physician 
and his professional rights. In the present circumstances, this appears impossible inside the European community that consists of mainly of former colonial powers that function with free market conditions but naturally with unfair trade terms [5].

In the era of economic crisis, the public hospital faces dramatic funding reductions while simultaneously service provision rises. Citizens meet the impossibility to access private sector health provision and resort to public sector healthcare [11]. In the present circumstances, the National Health System is called on to maintain at least its human capital. It is the administration of the hospital that takes the role of establishing the incentives in regards to the retention of the medical workforce.

Summarizing, the Greek economic crisis and its societal consequences create a mass exodus of talented and highly trained doctors who search for work with better prospects and rewards. In theory, many will return when the country starts to redevelop itself, but historical data indicates that after many years of emigration, repatriation is difficult and this makes it difficult for Greece in its effort to overcome its economic and social difficulties. In order to confront the situation, policies ought to have a simultaneous economic and humanistic approach to protect physicians who remain in the country with suitable motivational incentives [3].

\section{References}

[1] Kangasniemi, M., Winters, L.A. and Commander, S. (2007) Is the Medical Brain Drain Beneficial? Evidence from Overseas Doctors in the UK. Social Science \& Medicine, 65, 915-923. http://dx.doi.org/10.1016/j.socscimed.2007.04.021

[2] Beine, M., Docquier, F. and Rapoport, H. (2008) Brain Drain and Human Capital Formation in Developing Countries: Winners and Losers. The Economic Journal, 118, 631-652. http://dx.doi.org/10.1111/j.1468-0297.2008.02135.X

[3] Ifanti, A.A., Argyriou, A.A., Kalofonou, F.H. and Kalofonos, H.P. (2014) Physicians’ Brain Drain in Greece: A Perspective on the Reasons Why and How to Address It. Health Policy, 117, 210-215. http://dx.doi.org/10.1016/j.healthpol.2014.03.014

[4] Labiris, G., Gitona, K., Drosou, V. and Niakas, D. (2008) A Proposed Instrument for the Assessment of Job Satisfaction in Greek Mental NHS Hospitals. Journal of Medical Systems, 32, 333-341. http://dx.doi.org/10.1007/s10916-008-9138-8

[5] Stewart, J.B., Clark, D.A. and Clark, P.F. (2007) Migration and Recruitment of Healthcare Professionals: Causes, Consequences and Policy Responses. Focus Migration Policy Brief, No. 7.

[6] Zhatkanbaeva, A., Zhatkanbaeva, J. and Zhatkanbaev, E. (2012) The Impact of Globalization on "Brain Drain” in Developing Countries. Procedia Social and Behavioral Sciences, 47, 1490-1494. http://dx.doi.org/10.1016/j.sbspro.2012.06.848

[7] EINAP (2014) To the Minister of Health for the Medical Migration, 17/06/14. http://www.einap.gr http://www.einap.gr/index.php/association/announcement/association-announcements/599-metanasteusi

[8] Okeke, E.N. (2013) Brain Drain: Do Economic Conditions "Push” Doctors out of Developing Countries? Social Science \& Medicine, 98, 169-178. http://dx.doi.org/10.1016/j.socscimed.2013.09.010

[9] Kontodimopoulos, N., Paleologou, V. and Niakas, D. (2009) Identifying Important Motivational Factors for Professionals in Greek Hospitals. BMC Health Services Research, 9, 164. http://dx.doi.org/10.1186/1472-6963-9-164

[10] Mullan, F. (2005) The Metrics of the Physician Brain Drain. New England Journal of Medicine, 353, 1810-1818. http://dx.doi.org/10.1056/NEJMsa050004

[11] Tsounis, A., Sarafis, P. and Bamidis, P. (2014) Motivation among Physicians in Greek Public Health-Care Sector. British Journal of Medicine \& Medical Research, 4, 1094-1105. http://dx.doi.org/10.9734/BJMMR/2014/6821

[12] Dikaios, K., Koutouzis, M., Polizos, N., Sigalas, J. and Hletsos, M. (1999) Basic Management, Principles Management (Management) at Health Services. Publishing EAP, Patra.

[13] Maslow, A.H. (1943) Theory of Human Motivation. Psychological Review, 50, 370-396. http://dx.doi.org/10.1037/h0054346

[14] Herzberg, F. (1966) Work and the Nature of Man. World Publishing, Company, Cleveland.

[15] McClelland, D.C. (1953) The Achievement Motive. Appleton-Century-Crofts, New York. http://dx.doi.org/10.1037/11144-000

[16] Adams, S.J. (1963) Toward an Understanding of Inequality. Journal of Abnormal and Social Psychology, 67, $422-436$. http://dx.doi.org/10.1037/h0040968

[17] Gkorezis, P. and Petridou, E. (2012) The Effect of Extrinsic Rewards on Public and Private Sector Employees’ Psychological Empowerment: A Comparative Approach. The International Journal of Human Resource Management, 23, 3596-3612. http://dx.doi.org/10.1080/09585192.2011.639025 